\title{
PENINGKATAN PENGGUNAAN ANTIBIOTIK SECARA BIJAK MELALUI INTERVENSI ALIH PENGETAHUAN UNTUK MERUBAH PERSEPSI MASYARAKAT DI KABUPATEN BANYUMAS
}

\author{
Dwi Utami Anjarwati * \\ Universitas Jenderal Soedirman
}

Fajar Wahyu Pribadi

Universitas Jenderal Soedirman

Idsap Peramiarti

Universitas Jenderal Soedirman

\begin{abstract}
IMPROVED USE OF ANTIBIOTIC BY USING TRANSFER OF KNOWLEDGE INTERVENTIONS TO CHANGE THE COMMUNITY PERCEPTION IN BANYUMAS DISTRICT. The use of antibiotics without indication by the medical community and the community became the trigger factor of increasing the incidence of antibiotic resistance in Indonesia. Meanwhile by 20150 antibiotic resistance is predictedto be the leading cause of death in the world. Community devotion was aimed at improving the understanding of society so that that is a change of perception about the use of antibiotic wisely. The target respondents of devotion consists of member of the family welfare empowerment group (PKK). A seriaes of activities undertaken were pre and post test to measure respondents' understanding of antibiotic use before and after intervention in the transfer of knowledge. The questionnaire used previously tested its validity by Pearson product moment test and its reliability by Alpha-Cronbach. The Sharpening of material obtained in knowledge transfer was done with role play and discussion. The result of $T$ test analysis to score of quesionnaire before and after knowledge transfer showed significant $p$ value $(p=0,049)$. The conclusion was that the transfer of knowledge can change the perception of PKK members about the wise use of antibiotics.
\end{abstract}

KEYWORDS: Antibiotics, Perception, Use of antibiotics wisely.

* Corresponding Author: Bagian Mikrobiologi Fakultas Kedokteran Universitas Jenderal Soedirman; Jl. Gumbreg No 1, Berkoh, Purwokerto; Email: dzikrarana@gmail.com

Article History: Received: 24-9-2017; Revised: 11-10-2017; Accepted: 30-11-2017

Permalink: http://ppm.ejournal.id/index.php/pengabdian/article/view/24

How to cite (APA): Anjarwati, D. U., Pribadi, F. W. \& Peramiarti, I. (2017). Peningkatan penggunaan antibiotik secara bijak melalui intervensi alih pengetahuan untuk merubah persepsi masyarakat di kabupaten Banyumas. Jurnal Pengabdian Pada Masyarakat, 2(2), 93100.

This is an open access article distributed under the terms of the Creative Commons Attribution 4.0 International License, which permits unrestricted use, distribution, and reproduction in any medium, provided the original work is properly cited. @ 2017, Dwi Utami Anjarwati, Fajar Wahyu Pribadi, Idsap Peramiarti.

\section{PENDAHULUAN}

Masalah resistensi antibiotik yang sangat komplek tidak hanya terjadi di Indonesia tapi juga secara global. United Kingdom Prime Minister menyampaikan prediksi bahwa jika kasus resistensi antibiotik di seluruh dunia terus meningkat, maka pada tahun 2050 kematian akibat resistensi antibiotik mencapai 10 juta pertahun dan menjadi penyebab kematian tertinggi di antara penyebab lain. Beban 
Peningkatan Penggunaan Antibiotik Secara Bijak Melalui Intervensi Alih

Pengetahuan Untuk Merubah Persepsi Masyarakat di Kabupaten Banyumas

biaya sistem kesehatan yang harus ditanggung secara global mencapai 100 triliun USD pada tahun yang sama. (O’Neill, 2014)

Resistensi antibiotik ditemukan tidak hanya di rumah sakit, tetapi ditemukan pula di lingkungan masyarakat. Hasil penelitian tentang resistensi antibiotik di Indonesia, pada tahun 2000-2004 di RSUD Dr. Soetomo Surabaya dan RSUP dr. Kariadi Semarang, membuktikan bahwa sudah terdapat kuman multi-resisten seperti MRSA (Methicillin Resistant Staphylococcus aureus) dan bakteri penghasil ESBL (Extended Spectrum Beta Lactamases). Selain itu, penggunaan antibiotik yang tidak berdasarkan indikasi di temukan sebesar 30\% sampai 80\% (Moeloek, 2015b). Kasus karier methicillin resistant Staphylococcus aureus (MRSA) didapatkan $25 \%$ pada perawat rumah sakit swasta dan $14 \%$ pada perawat rumah sakit kabupaten Banyumas (Anjarwati et al, 2011). Penelitian tentang penggunaan antibiotik di Surabaya mendapatkan hasil bahwa antibiotik seperti amoksilin atau ampisilin, kloramfenikol, siprofloksasin, kotrimoksasol dan tetrasiklin dikonsumsi dalam waktu yang singkat (rata-rata tiga hari). Antibiotik tersebut diresepkan oleh dokter di rumah sakit (12\%), pusat pelayanan kesehatan (29\%), praktek pribadi $(36 \%)$, perawat dan bidan (6\%). Pembelian antibiotik secara bebas melalui apotek, toko obat, kios/toko obat tradisional Cina ditemukan 17\% (Hadi et al, 2008).

94 Sementara itu, hasil Riset Kesehatan Dasar (Riskesdas) pada tahun 2013 memberikan informasi bahwa 35,2\% rumah tangga menyimpan obat untuk swamedikasi. Sebanyak 35,2\% rumah tangga menyimpan obat dan 35,7\% diantaranya menyimpan obat keras dan antibiotika. Selanjutnya diketahui bahwa $27,8 \%$ di antaranya menyimpan antibiotik, dan $86,1 \%$ antibiotik tersebut diperoleh tanpa resep (Moeloek, 2015a).

Resistensi kuman terhadap antibiotik tersebut terjadi akibat penggunaan antibiotik yang tidak bijak di semua lini baik rumah sakit, tempat pelayanan kesehatan lain, dan masyarakat serta penerapan kewaspadaan standar (standard precaution) yang tidak benar di fasilitas pelayanan kesehatan. (Moeloek, 2015b) Penggunaan antibiotika yang bijak dan rasional baik di tempat pelayanan kesehatan maupun di masyarakat dapat mengurangi beban penyakit, khususnya penyakit infeksi. Sebaliknya, penggunaan antibiotika secara luas pada manusia dan hewan yang tidak sesuai indikasi, mengakibatkan meningkatnya resistensi antibiotika secara signifikan (Moeloek, 2015b).

Upaya pengendalian resistensi antibiotik telah banyak dilakukan melalui beberapa program terkait. Secara garis besar upaya untuk mengurangi masalah resistensi antibiotik adalah melalui 2 jalur, yaitu mendorong penggunaan antibiotik 
bijak dan mencegah penyebaran bakteri resisten. Komite pengendalian resistensi antibiotik (KPRA) dibentuk oleh Kementerian Kesehatan Republik Indonesia. Komite ini terdiri dari pengambil kebijakan bidang kesehatan, organisasi profesi, dan lembaga swadaya masyarakat untuk selalu dapat bekerja sama dalam mengawal program pengendalian resistensi antimikroba secara luas, baik di fasilitas pelayanan kesehatan maupun di masyarakat. (Moeloek, 2015b).

Prediksi angka kematian akibat resistensi antibiotik dan gambaran tingginya beban biaya kesehatan yang harus dikeluarkan pada tahun 2050 secara global serta kejadian resistensi antibiotik di rumah sakit maupun di masyarakat Indonesia dalam angka yang bervariasi serta penggunaan antibiotik yang kurang tepat menunjukkan bahwa program pengendalian resistensi antibiotik masih perlu ditingkatkan dengan berbagai upaya. Pengabdian masyarakat ini dilakukan sebagai upaya peningkatan pemahaman masyarakat sehingga terjadi perubahan persepsi tentang penggunaan antibiotik secara bijak.

\section{METODE PELAKSANAAN}

Responden dalam pengabdian masyarakat ini adalah anggota PKK RT 03/ RW 07, Bersole Wanadadi, Kelurahan Karang Pucung, Kecamatan Purwokerto Selatan, Kabupaten Banyumas. Kelompok PKK ini memiliki anggota kurang lebih 50 ibu-ibu. Alasan pemilihan responden adalah karena peran ibu yang strategis terkait urusan logistik dalam keluarga.

Skor persepsi masyarakat yang dinilai dengan menggunakan kuesioner. Validitas kuesioner telah diuji dengan uji Pearson product-moment, sementara reliabilitas kuesioner diuji dengan uji cronbach alpha. Kuesioner terdiri dari 10 item pernyataan dengan jawaban tertutup menggunakan skala likert. Pada pernyataan positif, bobot jawabannya adalah: pilihan jawaban sangat setuju (SS) = 5; pilihan jawaban setuju $(S)=4$; pilihan jawaban kurang setuju $(K S)=3$; pilihan jawaban tidak setuju (TS) $=2$; dan pilihan jawaban sangat tidak setuju $($ STS $)=1$. Pada pernyataan negatif, bobot jawaban berlaku sebaliknya, STS memiliki bobot tertinggi yaitu 5, dan seterusnya hingga SS memiliki bobot paling rendah yaitu 1 .

Pengisian Kuesioner I merupakan pretest yang bertujuan untuk mengetahui persepsi awal dari ibu-ibu PKK tentang bahaya resistensi antibiotik dan kondisi dasar yang memerlukan antibiotik. Alih pengetahuan (ranah afektif) tentang bahaya resistensi antibiotik dilakukan oleh narasumber dari bidang ilmu mikrobiologi dan farmakologi. Dalam alih pengetahuan ini digunakan alat peraga 
brosur, poster dan hasil pemeriksaan resistensi antibiotik dari metode Antibiotic susceptibility testing (AST).

Proses pengendapan materi dilakukan dengan metode roleplay yang bertujuan untuk mempertajam ranah psikomotor responden dalam pengenalan tanda-tanda penyakit dasar yang memerlukan antibiotik. Responden diberi simulasi kasus-kasus sederhana yang dapat dipahami secara awam. Responden juga diajak untuk berdiskusi dua arah terkait dengan pengetahuan yang telah diterima.

Post test diberikan untuk mengetahui pemahaman ibu-ibu PKK setelah rangkaian kegiatan alih pengetahuan tentang bahaya resistensi antibiotik dan kondisi dasar yang memerlukan antibiotik dengan mengisi kuesioner yang sama dengan saat pretest. Hasil pre dan post test dianalisis agar hasil kuesioner dapat diinterpretasikan dengan cara mengalikan jumlah responden dengan skor masingmasing alternatif yang dipilih pada tiap soal. Perbedaan nilai pre dan post test diuji dengan uji T berpasangan, dengan tingkat kemaknaan $p<0,05$.

\section{HASIL DAN PEMBAHASAN}

Responden pada pengabdian ini berjumlah 33. Semua anggota PKK yang hadir adalah 50 orang, 10 diantaranya tidak bersedia mengisi kuesioner. Tujuh hasil kuesioner tidak dapat dianalisis karena ditemukan jawaban lebih dari satu dalam satu item pernyataan. Deskripsi responden berdasarkan usia, pendidikan dan pekerjaan dituangkan dalam Tabel 1.

Usia responden terbanyak adalah pada rentang 31-40 tahun. Terbanyak kedua dalam prosentase yang seimbang adalah rentang usia 20-30 dan 51-60. Prosentase pendidikan terbanyak adalah SD, sementara jenis pekerjaan didominasi oleh ibu rumah tangga. Metode alih pengetahuan dalam pengabdian masyarakat ini masih relevan dengan melihat struktur usia responden yang didominasi oleh kelompok usia yang relatif muda. Pengaruh pendidikan yang didominasi oleh pendidikan tingkat SD terhadap keberhasilan alih pengetahuan diminimalisir dengan penguatan ilustrasi materi menggunakan metode roleplay. Dengan metode ini diharapkan materi yang disampaikan lebih berkesan, selanjutnya diperdalam dengan kesempatan berdiskusi tentang hal-hal yang belum dapat diterima dengan baik. Peran ibu rumah tangga dari sisi logistik sangat penting dalam pengambilan keputusan terkait penggunaan antibiotik dalam keluarganya. 
Tabel 1. Karakter Responden

\begin{tabular}{ccc}
\hline Kategori & Frekuensi & $\%$ \\
\hline Usia (thn): & & \\
$20-30$ & 6 & 18,2 \\
$31-40$ & 15 & 45,5 \\
$41-50$ & 3 & 9 \\
$51-60$ & 6 & 18,2 \\
$61-70$ & 3 & 9 \\
\hline Total & 33 & 100 \\
\hline Pendidikan: & & \\
SD & 21 & 63,7 \\
SMP & 7 & 21,2 \\
SMA & 5 & 15,1 \\
\hline Total & 33 & 100 \\
\hline Pekerjaan: & & \\
Ibu rumah tangga & 25 & 75,8 \\
Dagang & 4 & 12,1 \\
Buruh & 4 & 12,1 \\
\hline Total & 33 & 100 \\
\hline & &
\end{tabular}

Hasil analisis uji $\mathrm{T}$ terhadap skor pre dan post test dari kuesioner dalam pengabdian ini menunjukkan bahwa ada perbedaan bermakna signifikan ( $\mathrm{p}=$ 0,0492) antara hasil skor pre dan post test. Hal ini memberikan informasi bahwa bila skor pre dan post test sama, maka 4\% saja peluang untuk hipotesis nol diterima. Oleh karena itu, jika hipotesis nol (tidak ada beda skor pre dan post test setelah alih pengetahuan) ditolak (ada beda antara skor pre dan post test) maka dapat dikatakan bahwa alih pengetahuan ini dapat menyebabkan perbedaan skor pre dan post test.

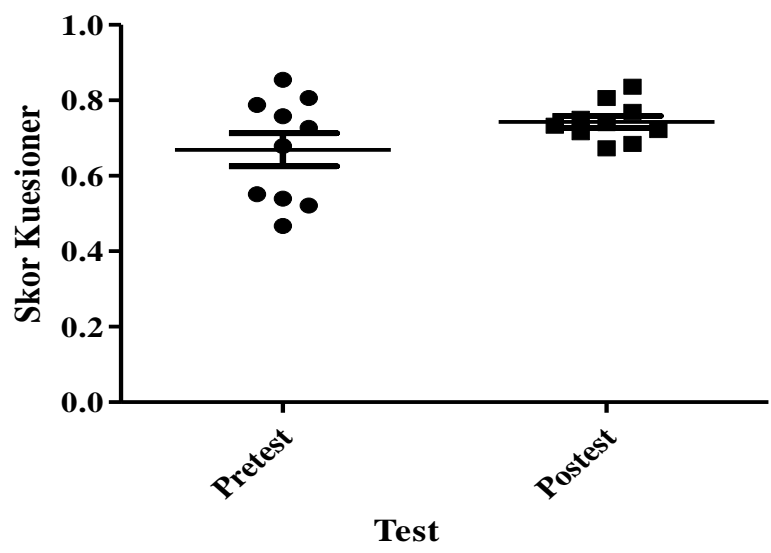

Gambar 1. Scatter Plot interpretasi skor kuesioner Pre dan Post test 
Dua item pertanyaan memiliki skor pretest yang lebih tinggi dibandingkan skor post test. Sementara satu item pertanyaan memiliki skor yang sama baik pretest maupun post test. Nilai pretest yang lebih rendah dibandingkan nilai post test didapatkan pada tujuh item pertanyaan lain. Alasan ini mendasari bahwa nilai p $(0,0492)$ meskipun bermakna secara statistik, tetapi kemaknaannya tidak terlalu tinggi. Rerata skor pre test adalah 0,67 dan post test sebesar 0,75, seperti tampak pada Tabel 2 dan Scatter Plot yang dsajikan pada Gambar 1. Hasil evaluasi terhadap skor kuesioner memberikan informasi bahwa alih pengetahuan menyebabkan peningkatan pemahaman yang dapat merubah persepsi masyarakat tentang penggunaan antibiotik menjadi lebih bijak.

Tabel 2. Interpretasi skor hasil pengamatan Pre dan Post Test

\begin{tabular}{llcc}
\hline No. & Skor & K1 x Skor & K2 x Skor \\
\hline 1. & Pernyataan 1 & 0,79 & 0,75 \\
\hline 2. & Pernyataan 2 & 0,79 & 0,75 \\
\hline 3. & Pernyataan 3 & 0,47 & 0,68 \\
\hline 4. & Pernyataan 4 & 0,85 & 0,84 \\
\hline 5. & Pernyataan 5 & 0,55 & 0,72 \\
\hline 6. & Pernyataan 6 & 0,81 & 0,81 \\
\hline 7. & Pernyataan 7 & 0,73 & 0,77 \\
\hline 8. & Pernyataan 8 & 0,52 & 0,74 \\
\hline 9. & Pernyataan 9 & 0,54 & 0,67 \\
\hline 10. & Pernyataan 10 & 0,68 & 0,73 \\
\hline & Rerata & 0,67 & 0,74 \\
\hline
\end{tabular}

Keterangan $\mathrm{K} 1=$ Pre test $; \mathrm{K} 2$ Post test

Informasi yang disampaikan dalam pengabdian masyarakat ini selaras dengan informasi yang disampaikan dalam penelitian yang berjudul pengaruh penyuluhan penggunaan antibiotik terhadap tingkat pengetahuan masyarakat di Kota Medan. Pada penelitian tersebut disimpulkan bahwa penyuluhan mempengaruhi perubahan tingkat pengetahuan masyarakat tentang penggunaan antibiotik (Wowiling et al, 2013).

Alih pengetahuan merupakan salah satu langkah yang dapat dilakukan dalam merubah persepsi masyarakat karena tidak hanya sebatas berbagi pengatahuan namun diharapkan terjadi akuisisi dan penerapan pengetahuan tersebut oleh pihak yang diberi pengetahuan sehingga memperbaiki persepsi yang pada awalnya keliru. Alih pengetahuan meliputi pula penyusunan informasi tugas dan pengetahuan untuk berkolaborasi dengan orang lain untuk membantu dan 
memecahkan masalah terkait penggunaan antibiotik yang kurang bijak pada masyarakat (Aliakbar et al, 2012). Keterampilan dalam mengenali kondisi yang memerlukan antibiotik diharapkan dapat diterapkan dalam kehidupan sehari-hari ketika dihadapkan pada pilihan menggunakan antibiotik atau tidak dan mengurangi pembelian antibiotik secara bebas tanpa resep.

\section{SIMPULAN}

Metode alih pengetahuan yang diperdalam dengan metode role play dalam pengabdian masyarakat di Kabupaten Banyumas ini dapat merubah persepsi masyarakat tentang penggunaan antibiotik secara bijak.

\section{REFERENSI}

Aliakbar, E., Yusoff, R. B., \& Mahmood, N. H. N. (2012). Determinants of knowledge sharing behavior. IPEDR, 29, 208-215.

Anjarwati, D. U., Setyono, J., \& Rujito, L. (2011). Perawat kesehatan sebagai karier methicillin resistant staphylococcus aureus (MRSA) di rumah sakit pemerintah dan rumah sakit swasta Kabupaten Banyumas. Mandala of Health, 5(1).

Hadi, U., Duerink, D. O., Lestari, E. S., Nagelkerke, N. J., Werter, S., Keuter, M., Suwandojo, E., Rahardjo, E., Broek, P. V. D., \& Gyssens, I. C. (2008). Survey of antibiotic use of individuals visiting public healthcare facilities in Indonesia. International Journal of Infectious Diseases, 12(6), 622-629. doi:10.1016/j.ijid.2008.01.002

Moeloek, N. D. F. (2015a). Menkes canangkan gerakan masyarakat cerdas menggunakan obat. Retrieved July 20, 2017, from website: http://www.depkes.go.id/article/view/15111900001/menkes-canangkangerakan-masyarakat-cerdas-menggunakan-obat.html.

Moeloek, N. D. F. (2015b). Penggunaan antibiotik bijak dan rasional kurangi beban penyakit infeksi. Pusat Komunikasi Publik Sekretariat Jenderal Kementerian Kesehatan RI

O'Neill, J. (2014). Antimicrobial resistance: tackling a crisis for the health and wealth of nations. The Review on Antimicrobial Resistance. Wellcome Trust and the UK Government. 
Wowiling, C., Goenawi, L. R., \& Citraningtyas, G. (2013). Pengaruh penyuluhan penggunaan antibiotika terhadap tingkat pengetahuan masyarakat di Kota Manado. PHARMACON, 2(3) 24-28.

\section{Ucapan Terimakasih}

Terima kasih kepada Universitas Jenderal Soedirman, Purwokerto yang terlah mendanai kegiatan pengabdian masyarakat ini melalui program penerapan Ipteks. 